\title{
Assessing the Rate of Successful Induction of labor Following Intra- Vaginal Administration of Misoprostol
}

\author{
Dr. Milia Tamanna Rahman ${ }^{1 *}$, Dr. Syed Abdus Sobhan ${ }^{2}$ \\ ${ }^{1}$ Registrar (Obstetrics and Gynaeocology), Sylhet MAG Osmani Medical College hospital, Sylhet, Bangladesh \\ ${ }^{2}$ Assistant professor (Orthopaedic Surgery), Sylhet MAG Osmani Medical College, Sylhet, Bangladesh
}

DOI: $10.36348 /$ sijog.2022.v05i01.002 | | Received: 02.12.2021 | Accepted: 11.01 .2022 | Published: 18.01 .2022

*Corresponding author: Dr. Milia Tamanna Rahman,

Registrar (Obstetrics and Gynaeocology), Sylhet MAG Osmani Medical College hospital, Sylhet, Bangladesh

\section{Abstract}

Introduction: The use of prostaglandin preparations with or without oxytocin infusion is widely recognized and accepted as a standard method of induction of labor. It has been shown to reduce induction time and the risk of failed induction. But the use of prostaglandin E2 is quite expensive and is not available in many developing countries. In such cases, misoprostol can also be used as an induction agent. The aim of the study was to assess the rate of successful induction of labor following intra-vaginal administration of misoprostol. Methods: This open clinical trial study was conducted at the Department of Obstetrics and Gynaecology, North East Medical College Hospital, Sylhet, Bangladesh. The study duration was 1 year and was conducted with a total of 100 patients who were admitted with term pregnancy and unfavorable cervix in the study hospital, fulfilling the inclusion and exclusion criteria. Result: Bishop's score was significantly raised after 6 hours vaginal misoprostol [4.63 (SD \pm 1.17 ) VS 5.82 (SD \pm 1.60$)$; p <0.001]. The mean induction to vaginal delivery time was 14.6 ( $\mathrm{SD} \pm 4.6$ ) hours (range 6 to 23 hours); the induction to vaginal delivery time was $<12$ hours in $44.3 \%$ and $12-24$ hours in $55.7 \%$ cases. The mode of delivery was vaginal in most of the cases $(70.0 \%)$ and cesarean section was in $30.0 \%$ of cases. Fetal distress was the most frequent indication of cesarean section (63.3\%), followed by arrested labor $(20.0 \%)$ and failed induction $(16.7 \%)$. The maternal obstetric complication was postpartum hemorrhage $(3.0 \%)$ without any ruptured uterus, tachysystole, hypertonus uterus, or hyperstimulation. The maternal sideeffects were nausea or vomiting (5.0\%), diarrhea (2.0\%), and fever (1.0\%). Fetal outcomes were, normal baby (65.0\%), APGAR score $<7$ at $1 \mathrm{~min}(27.0 \%)$, resuscitation needed (27.0\%), neonatal unit admission (13.0\%), meconium passage $(8.0 \%)$ and intrauterine Fetal death (diagnosed before induction) $(8.0 \%)$. Conclusion: Vaginal misoprostol seems to be a promising drug for labor induction with a high rate of success. Possible advantages of misoprostol may be the availability, ease of administration, well tolerability, and most notably its dual action in cervical ripening and labor induction. However, future studies focusing on dosing regimens and routes of application are needed.

Keywords: Induction, Misoprostol, Intravaginal.

Copyright (C) 2022 The Author(s): This is an open-access article distributed under the terms of the Creative Commons Attribution 4.0 International License (CC BY-NC 4.0) which permits unrestricted use, distribution, and reproduction in any medium for non-commercial use provided the original author and source are credited.

\section{INTRODUCTION}

Induction of labor may be necessary if the mother or fetus is at risk if the pregnancy is allowed to continue. The decision between Cesarean Section and induction of labor is influenced by maternal condition, Fetal condition and gestational period, cervical ripening, and bony pelvic dimension. The success of induction is heavily reliant on the cervix's consistency, compliance, and arrangement. In approximately ten percent of all pregnancies, women have an unfavorable cervix and require labor to be induced. When labor is induced in an unripe cervix it is associated with a higher-than-normal incidence of failure of induction, prolonged labor, instrumental delivery, and cesarean section [1]. Labor induction in the presence of an unfavorable cervix is often prolonged, tedious, and remains a well-recognized impediment to the success of induction of labor [2]. A simple efficient method of ripening the cervix before induction is, therefore, clearly of use. Various methods have been used to ripen the cervix before induction at labor to increase the success rate [1]. It is generally understood that induction of labor can be difficult and often failed in situations of an immature cervix. The use of medications to ripen the cervix before typical induction 
procedures is an increasingly common practice. Prostaglandin E2 gel is used for cervical ripening and labor induction. These are, however, costly and need to be stored in a refrigerator at a temperature of 2-80C and its half-life is 18 months. Moreover, the tablet form of prostaglandin E2 is not available in many developing countries, including Bangladesh [3]. Oxytocin and prostaglandins (PGs) are the agents most frequently used for the induction of labor. Although oxytocin is commonly acknowledged as a safe and efficient uterine contraction initiator, its success is reliant on the state of the cervix at the start of induction. In a woman with an unfavorable cervix, cervical ripening agents are often applied before oxytocin therapy is initiated [4]. Numerous studies have shown locally applied prostaglandin's (PG), principally PGE 2 and PGE 1, to increase cervical compliance and dilatation [5]. But risks associated with the use of prostaglandins often include uterine hyperstimulation accompanying Fetal heart rate (FHR) changes [6-8]. Misoprostol use also has its own risk. Major complications after high doses of misoprostol include uterine hyperstimulation and uterine rupture [9]. Misoprostol is a synthetic PGE1 analog that is a safe and inexpensive agent for cervical ripening [10-12]. Misoprostol has a number of advantages for clinical obstetric and gynecologic use. It costs approximately 100 times less than other prostaglandins, has a long shelf life, is easy to administer, and does not require refrigeration. Furthermore, it is registered in more than 80 countries including Bangladesh, and is therefore widely available $[1,13]$. The objective of this study is to determine the efficacy and safety of intra-vaginal administration of misoprostol in the induction of labor by observing successful induction cases after intra-vaginal administration of misoprostol.

\section{OBJECTIVE}

\section{General Objective}

- To assess the rate of successful induction of labor following intra-vaginal administration of misoprostol.

\section{Specific Objectives}

- To assess the safety and efficacy of misoprostol in the induction of labor

\section{METHODS}

This open clinical trial study was conducted at the Department of Obstetrics and Gynaecology, North East Medical College Hospital, Sylhet, Bangladesh. The study duration was 1 year, from $1^{\text {st }}$ January 2011 to the $31^{\text {st }}$ of December, 2011. The sample size for this study was determined to be 96 by using Cochran's formula considering a $5 \%$ level of significance, but in this study, 100 patients with term pregnancy and unfavorable cervix and fulfilled the inclusion and exclusion criteria were enrolled. All patients admitted with term pregnancy and unfavorable cervix in the study hospital, fulfilling the inclusion and exclusion criteria were enrolled as the study population in this study. A consecutive, convenient and purposive sampling technique was applied to collect the sample. After admission of the patients, history was taken and clinical examination was done. Informed written consent was obtained from each of the patients, and ethical approval was obtained from the ethical review committee of the study hospital. One hundred women were assigned to receive $50 \mu \mathrm{gm}$ intra-vaginal misoprostol intravaginally. Assessment of cervix was done before application of medication and documented. For women who were selected for vaginal misoprostol, an initial dose of $50 \mu \mathrm{gm}$ was applied in the posterior vaginal fornix. If labor did not establish within 6 hours subsequent doses of $50 \mu \mathrm{gm}$ were applied 6 hourly maximum up to 4 doses. After delivery, both the mother and neonate were followed for 48 hours or until hospital discharge, whichever came sooner. All relevant necessary information and clinical data were recorded in a predesigned datasheet.

\section{Inclusion Criteria}

- Patients with term pregnancy with single-tone baby without labor pain

- Patients who had given consent to participate in the study.

- Cephalic presentation

- Adequate pelvis

- $\quad$ Bishop score $<6$

- Patients with IUFD, GDM (Size baby $2.5-3.5 \mathrm{~kg}$, estimated by USG), Post-dated pregnancy, Preeclampsia, eclampsia, Rh-negative mother.

\section{Exclusion Criteria}

- Pregnancy less than 37 weeks

- Cephalopelvic disproportion

- Previous cesarean section or myomectomy or hysterotomy

- Antepartum hemorrhage

- $\quad$ Grand multipara $(\geq 4)$

- Vaginal infection

- Known hypersensitivity to prostaglandin

- Unable to answer the criteria question.

- Exclude those affected with other chronic diseases etc.

\section{RESULTS}

The age of the participants ranged from 18 to 32 years, with the mean age being 22.4 ( $\mathrm{SD} \pm 2.9$ ) years. Bishop's score was significantly raised after 6 hours vaginal misoprostol $[4.63(\mathrm{SD} \pm 1.17)$ VS 5.82 $(\mathrm{SD} \pm 1.60) ; \mathrm{p}<0.001]$. The mean induction to vaginal delivery time was 14.6 ( $\mathrm{SD} \pm 4.6$ ) hours (range 6 to 23 hours); the induction to vaginal delivery time was $<12$ hours in $44.3 \%$ and $12-24$ hours in $55.7 \%$ cases. The mode of delivery was vaginal in most of the cases (70.0\%) and cesarean section was in $30.0 \%$ of cases. Fetal distress was the most frequent indication of 
cesarean section $(63.3 \%)$, followed by arrested labor $(20.0 \%)$ and failed induction $(16.7 \%)$. The maternal obstetric complication was postpartum hemorrhage $(3.0 \%)$ without any ruptured uterus, tachysystole, hypertonus uterus, or hyperstimulation. The maternal side-effects were nausea or vomiting $(5.0 \%)$, diarrhea
$(2.0 \%)$, and fever $(1.0 \%)$. Fetal outcomes were, normal baby (65.0\%), APGAR score $<7$ at $1 \mathrm{~min}(27.0 \%)$, resuscitation needed $(27.0 \%)$, neonatal unit admission (13.0\%), meconium passage $(8.0 \%)$ and intrauterine Fetal death (diagnosed before induction) (8.0\%).

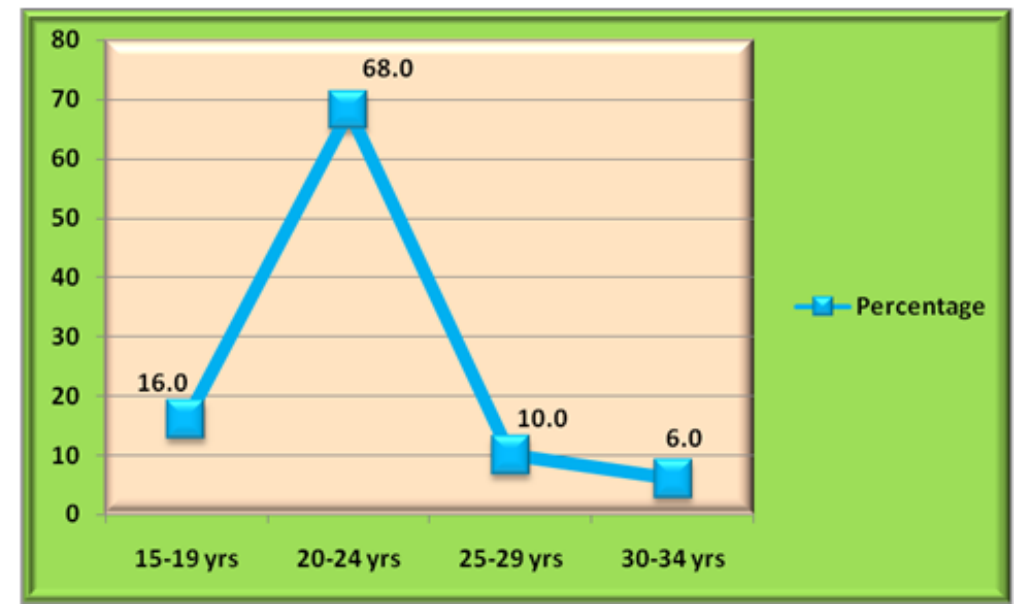

Fig-1: Distribution of the patients by age group $(n=100)$

The age of the patients ranged from 18 to 32 years with a mean age of $22.4(\mathrm{SD} \pm 2.9)$ years. Figure 1 showed the distribution of the patients based on age group. There were $68(68.0 \%)$ patients in the age group of 20-24 years, $16(16.0 \%)$ patients in the age group of $15-19$ years, $10(10.0 \%)$ patients in the age group of 25 29 years, and $6(6.0 \%)$ patients in the age group of 30 34 years.

Table-1: Distribution of the patients by causes of induction (n-100)

\begin{tabular}{|l|l|l|}
\hline Indication of induction & Frequency & Percentage \\
\hline Postdated pregnancy & 63 & 63.0 \\
\hline Pregnancy Induced Hypertension & 24 & 24.0 \\
\hline Gestational Diabetes Mellitus & 5 & 5.0 \\
\hline $\begin{array}{l}\text { Intrauterine Fetal Death } \\
\text { (diagnosed before induction) }\end{array}$ & 8 & 8.0 \\
\hline Total & $\mathbf{1 0 0}$ & $\mathbf{1 0 0 . 0}$ \\
\hline
\end{tabular}

Distribution of the patients on the basis of causes of induction was shown in table-3.1. Post-dated pregnancy was the most frequent indication of induction $(63.0 \%)$, followed by pregnancy-induced hypertension $(24.0 \%)$, intrauterine Fetal death (diagnosed before induction) $(8.0 \%)$, and gestational diabetes mellitus $(5.0 \%)$.

Table-2: Distribution of the patients by Bishop's score before and 6 hours after induction $(\mathrm{n}=100)$

\begin{tabular}{|l|l|l|l|}
\hline Bishop score & $\begin{array}{l}\text { Before } \\
\text { induction }\end{array}$ & $\begin{array}{l}\text { 6 hours after } \\
\text { induction }\end{array}$ & \multirow{2}{*}{ p-value } \\
\hline Mean & 3.32 & 5.82 & \multirow{2}{*}{$\mathrm{p}<0.001)$} \\
\cline { 1 - 3 } Standard deviation & 0.96 & 1.60 & \\
\hline Range & $2-5$ & $2-8$ & \\
\hline
\end{tabular}

*Paired t-test was done to find out the level of significance.

Bishop's score before induction (vaginal misoprostol) ranged from 2 to 5 with the mean of 3.32 $(\mathrm{SD} \pm 0.96)$ and Bishop's score 6 hours after induction (vaginal misoprostol) ranged from 2 to 8 with the mean of 5.82 ( $\mathrm{SD} \pm 1.60)$. Bishop's score was significantly raised 6 hours after vaginal administration of misoprostol $\quad(p<0.001)$. Table-3.2 showed the distribution of the patients by Bisop score before and 6 hours after induction. 


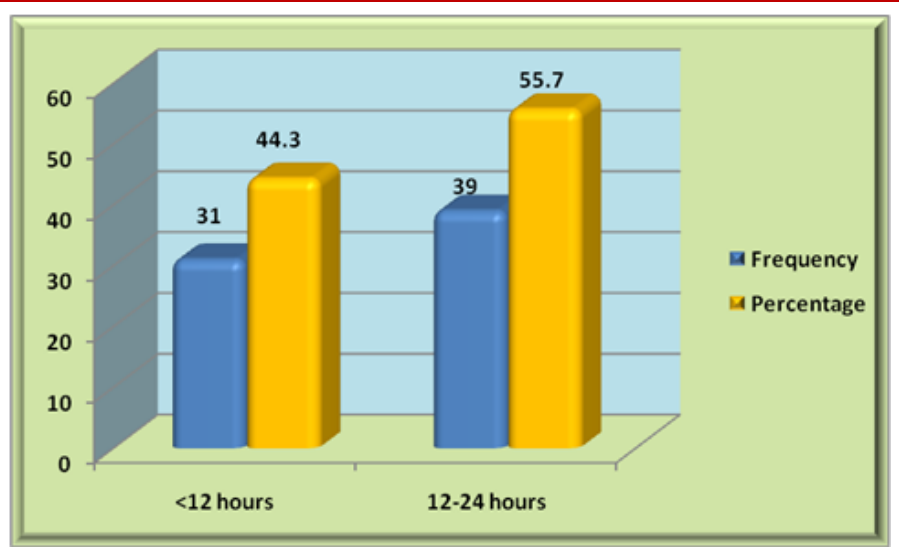

Fig-2: Distribution of the patients by induction to vaginal delivery time $(n=70)$

The induction to vaginal delivery time ranged from 6 to 23 hours with the mean of 14.6 (SD \pm 4.6 ) hours. Figure 2 showed the distribution of the patients by induction-vaginal delivery time. Induction-vaginal delivery time $<12$ hours was in 31 patients $(44.3 \%)$ and $12-24$ hours in 39 patients $(55.7 \%)$.

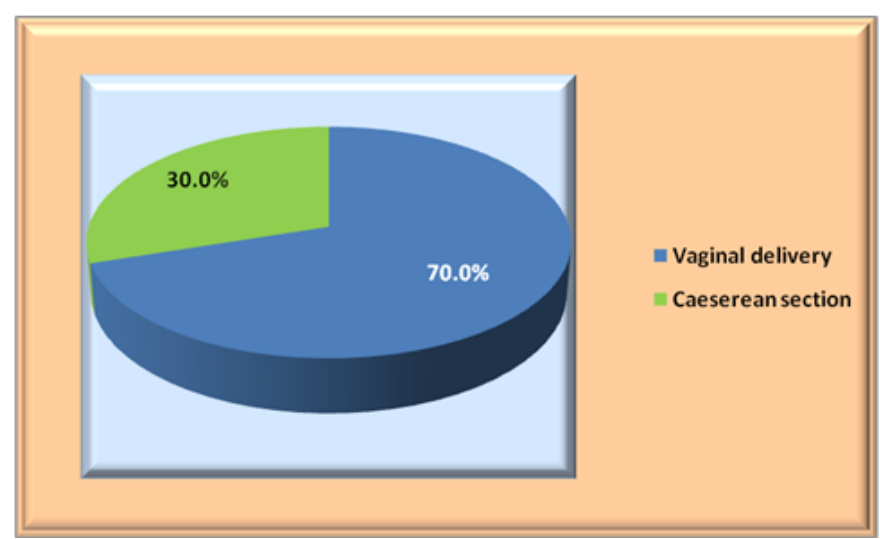

Fig-3: Distribution of patients according to mode of delivery $(n=100)$

Figure 3 showed the distribution of patients according to the mode of delivery. Mode of delivery was vaginal in most of the cases $[70(70.0 \%)$ and cesarean section in 30 patients (30.0\%)].

Table-3: Distribution of patients according to the indication of cesarean section $(n=30)$

\begin{tabular}{|l|l|l|}
\hline Indication of cesarean section & Frequency & Percentage \\
\hline Fetal distress & 19 & 63.3 \\
\hline Failure to progress of labor & 6 & 20.0 \\
\hline Failed induction of labor & 5 & 16.7 \\
\hline Total & 30 & 100.0 \\
\hline
\end{tabular}

Fetal distress was the most frequent indication of cesarean section $(63.3 \%)$, followed by arrested labor $(20.0 \%)$ and failed induction $(16.7 \%)$. The distribution of patients according to the indication of cesarean section was shown in table-3.

Table-4: Distribution of patients by characteristics of labor and maternal outcome (n=100)

\begin{tabular}{|l|l|l|}
\hline Variables & Frequency & Percentage \\
\hline Labor & 23 & 23.0 \\
\hline Oxytocin augmentation & 23 & 0.0 \\
\hline Tachysystole & 0 & 0.0 \\
\hline Hypertonus uterus & 0 & 0.0 \\
\hline Hyperstimulation & 0 & 3.0 \\
\hline Maternal outcome & 3.0 & 0.0 \\
\hline Postpartum hemorrhage & 3.0 & \\
\hline Ruptured uterus & 0 &
\end{tabular}


Milia Tamanna Rahman et al; Sch Int J Obstet Gynec, Jan. 2022; 5(1): 7-13

Distributions of patients by characteristics of labor and maternal outcome were shown in table 4 . During labor, oxytocin augmentation was required in
$23.0 \%$ cases and postpartum hemorrhage in $3.0 \%$ cases but no ruptured uterus, hyperstimulation, tachysystole, or hypertonus uterus.

Table-5: Distribution of patients by maternal side-effects $(n=100)$.

\begin{tabular}{|l|l|l|}
\hline Maternal side-effects & Frequency & Percentage \\
\hline Nausea/vomiting & 5 & 5.0 \\
\hline Diarrhoea & 2 & 2.0 \\
\hline Fever & 1 & 1.0 \\
\hline
\end{tabular}

Maternal side-effects observed were nausea or vomiting in $5.0 \%$, diarrhea in $2.0 \%$, and fever in $1.0 \%$.

Table-6: Distribution of patients according to Fetal outcome $(n=100)$

\begin{tabular}{|l|l|l|}
\hline Fetal outcome & Frequency & Percentage \\
\hline Normal baby & 65 & 65.0 \\
\hline APGAR score<7 at 1 min & 27 & 27.0 \\
\hline Resuscitation needed & 27 & 27.0 \\
\hline Needed Neonatal unit admission & 13 & 13.0 \\
\hline Meconium passage & 8 & 8.0 \\
\hline $\begin{array}{l}\text { Intrauterine Fetal death (diagnosed } \\
\text { before induction) }\end{array}$ & 8 & 8.0 \\
\hline
\end{tabular}

65 baby were normal $(65.0 \%), 27$ baby's APGAR score $<7$ at $1 \mathrm{~min}(27.0 \%)$, resuscitation needed $27(27.00 \%)$, needed neonatal unit admission 13 $(13.0 \%)$, meconium passage $08(8.0 \%)$ and intrauterine Fetal death $08(8.0 \%)$ (diagnosed before induction).

\section{DISCUSSION}

In the 20th century, indications for labor induction have focused increasingly on preeclampsia (toxemia) and postdates [14]. Labor induction, also known as inducing labor, is the artificial stimulation of uterine contractions during pregnancy prior to the onset of labor in order to promote a vaginal delivery. A health care physician may propose labor induction for a variety of reasons, most notably when a mother's or baby's health is jeopardized. Cervical ripening, or how soft and swollen the cervix is, is one of the most critical markers in predicting the chance of successful labor induction [15]. Labor induction often becomes necessary for patients when they are 2 weeks or more behind their due date, in cases of the unripe cervix, or when there might be other risk factors for the children. The use of agents to ripen the cervix before conventional methods of induction is now standard practice. Here, various methods can be used for induction of labor, including the use of inducing agents like prostaglandins, misoprostol, mifepristone, oxytocin, and relaxin. The present study was based on a clinical trial conducted in the Department of the Obstetrics and Gynaecology, North East Medical College Hospital, Sylhet during the period from 1st January 2011 to 31st December 2011with a view to finding out the efficacy and safety of intra-vaginal administration of misoprostol in cervical ripening and induction of labor in women with unfavorable cervix in term pregnancy. In this study, the age of the patients ranged from 18 to 32 years with a mean age of 22.4 (SD \pm 2.9 ) years. This was similar to the findings of Abbasi et al., where the mean age was $22(\mathrm{SD} \pm 5.2)$ years. ${ }^{[16]}$ In a few other similar studies, the mean age was similar but slightly higher $[1,17,18]$. We also observed that there were $68(68.0 \%)$ patients in the age group of 20 24 years, $16(16.0 \%)$ patients in the age group of $15-19$ years, $10(10.0 \%)$ patients in the age group of 25-29 years and $6(6.0 \%)$ patients in the age group of 30-34 years. This study observed the gestational age of the patients ranging from 38 to 42 weeks with the mean gestational age of 40.5 ( $\mathrm{SD} \pm 1.3$ ) weeks. This was similar to the findings of multiple other studies $[17,18]$. While observing the indication of induction of labor among the 100 study participants, postdated pregnancy was the most frequent indication of induction, observed in $63.0 \%$ of cases. Hypertension was observed in $24 \%$, intrauterine Fetal death (diagnosed before induction) was observed in $8.0 \%$, and the remaining $5 \%$ had gestational diabetes mellitus. These findings were in line with the findings of Chowdhury et al., who found similar indications of induction [17]. The Bishop's score, a medical system used to determine how long till possible labor, was measured for the patients before induction and 6 hours after induction. Bishop's score before induction (vaginal misoprostol) ranged from 2 to 5 with the mean of $3.32(\mathrm{SD} \pm 0.96)$ and Bishop's score 6 hours after induction (vaginal misoprostol) ranged from 2 to 8 with the mean of $5.82(\mathrm{SD} \pm 1.60)$. This elevation of the Bishop's Score was statistically significant. A similar significance was observed in a study by Agarwal [2]. Wing et al. observed a significant improvement of the Bishop's score at 3 hours after the intervention [19]. The mean score before and after the intervention was 2 and 4 respectively in their study. Similar to our study, Buser et al. also used $50 \mathrm{mg}$ of intravaginal misoprostol and observed a mean improvement of $3.5 \pm 2.1$ from the pre-induction score 
Milia Tamanna Rahman et al; Sch Int J Obstet Gynec, Jan. 2022; 5(1): 7-13

[20]. In our study, $70 \%$ of patients had a vaginal delivery, while $30 \%$ had a cesarean section. This result was supported by the findings of Shetty et al., where the mode of delivery after induction with vaginal misoprostol was vaginal in $72 \%$ and cesarean section in $28 \%$. ${ }^{[21]}$ Induction to the vaginal delivery time ranged from 6 to 23 hours with a mean of $14.6(\mathrm{SD} \pm 4.6$ ) hours. Almost similar results were observed in multiple other studies [22, 23]. The induction to the vaginal delivery time of $<12$ hours were observed in 31 patients $(44.3 \%)$, and $12-24$ hours in 39 patients $(55.7 \%)$. For the 30 patients who went through cesarean section, Fetal distress was the most frequent indication, present in $63.3 \%$ of cases. $20 \%$ had arrested labor and the remaining 5 patients $(16.7 \%)$ had failed induction of labor. These indications were similar to the findings of Chowdhury et al. [17]. Observing the labor and maternal outcomes of the 100 participants of our study, oxytocin augmentation was required for $23.0 \%$ of cases, while postpartum hemorrhage was observed in $3.0 \%$ of the patients. No ruptured uterus, hyperstimulation, tachysystole, or hypertonus uterus was observed in our study. This was considerably better compared to some other studies where these problems were also recorded $[12,17]$ maternal side effects were observed in a total of $8 \%$ of patients in this study. $5 \%$ had experienced nausea or vomiting, $2 \%$ had a fever, and 1 patient had a fever. These ratios were much lower compared to other previous studies $[12,24]$. Fetal outcome was normal for $65 \%$ of the cases of the present study. $27 \%$ had APGAR score $<7$ at $1 \mathrm{~min}$ of birth, and resuscitation was necessary for these children. Admission at the neonatal unit was necessary for $13 \%$, Meconium passage was observed in 8 cases, and in another 8 cases, intrauterine Fetal death was observed, which was diagnosed before the induction, and the primary cause of induction.

\section{Limitations of The Study}

The study was conducted in a single hospital with a small sample size. So, the results may not represent the whole community. The study did not have a long-term follow-up plan to better observe possible complications.

\section{CONCLUSION}

Bishop's score was significantly raised after 6 hours vaginal misoprostol. The mean induction to vaginal delivery time ranged from 6 to 23 hours, and the mean delivery time was $14.6(\mathrm{SD} \pm 4.6)$ hours; the induction to vaginal delivery time was $<12$ hours in $44.3 \%$ and $12-24$ hours in $55.7 \%$ cases. Vaginal delivery had the highest prevalence, and Fetal distress was the most common indication of cesarean section. Maternal obstetric complications were much lower compared to other similar studies. In conclusion, vaginal misoprostol seems to be a promising drug for labor induction. Possible advantages of misoprostol may be the availability, ease of administration, well tolerability, and most notably its dual action in cervical ripening and labor induction. However, future studies focusing on dosing regimens and routes of application are needed.

\section{RECOMMENDATION}

Close monitoring of labor, intrapartum CTG, and maintenance of partogram is mandatory for using vaginal misoprostol preparations.

Funding: No funding sources

Conflict of interest: None declared

Ethical approval: The study was approved by the Institutional Ethics Committee

\section{REFERENCES}

1. Akter, S., Chowdhury, S. B., \& Fatema, N. (2010). A comparison of orally administered misoprostol with vaginally administered misoprostol for cervical ripening and labour induction. Orion Medical Journal, 33(1), 710-713.

2. Agarwal, N., Gupta, A., Kriplani, A., \& Bhatla, N. (2003). Six hourly vaginal misoprostol versus intracervical dinoprostone for cervical ripening and labor induction. Journal of obstetrics and gynaecology research, 29(3), 147-151.

3. Blanchard, K., Clark, S., Winikoff, B., Gaines, G., Kabani, G., \& Shannon, C. (2002). Misoprostol for women's health: a review. Obstetrics \& gynecology, 99(2), 316-332.

4. Sanchez-Ramos, L., Kaunitz, A. M., Wears, R. L., Delke, I., \& Gaudier, F. L. (1997). Misoprostol for cervical ripening and labor induction: a metaanalysis. Obstetrics \& gynecology, 89(4), 633-642.

5. Ferdous, J. A., Khanam, N. N., Begum, M. R., \& Akhter, S. (2009). Cervical Ripening: Comparative Study between Intracervical Balooning by Foley s Catheter and Intravaginal Misoprostol Tablet. Journal of Bangladesh College of Physicians and Surgeons, 27(1), 5-12.

6. Goldman, J. B., \& Wigton, T. R. (1999). A randomized comparison of extra-amniotic saline infusion and intracervical dinoprostone gel for cervical ripening. Obstetrics \& Gynecology, 93(2), 271-274.

7. Schreyer, P. E. T. E. R., Sherman, D. J., Ariely, S. H. L. O. M. O., Herman, A. R. I. E., \& Caspi, E. L. I. A. H. U. (1989). Ripening the highly unfavorable cervix with extra-amniotic saline instillation or vaginal prostaglandin E2 application. Obstetrics and gynecology, 73(6), 938-942.

8. Kelly, A. J., Malik, S., Smith, L., Kavanagh, J., \& Thomas, J. (2009). Vaginal prostaglandin (PGE2 and PGF2a) for induction of labour at term. Cochrane database of systematic reviews, (4).

9. Wing, D. A. (1999). Labor induction with misoprostol. American journal of obstetrics and gynecology, 181(2), 339-345. 
Milia Tamanna Rahman et al; Sch Int J Obstet Gynec, Jan. 2022; 5(1): 7-13

10. Buccellato, C. A., Stika, C. S., \& Frederiksen, M. C. (2000). A randomized trial of misoprostol versus extra-amniotic sodium chloride infusion with oxytocin for induction of labor. American journal of obstetrics and gynecology, 182(5), 10391044.

11. Sanchez-Ramos, L., \& Kaunitz, A. M. (2000). Misoprostol for cervical ripening and labor induction: a systematic review of the literature. Clinical obstetrics and gynecology, 43(3), 475-488.

12. Zahran, K. M., Shahin, A. Y., Abdellah, M. S., \& Elsayh, K. I. (2009). Sublingual versus vaginal misoprostol for induction of labor at term: A randomized prospective placebo-controlled study. Journal of Obstetrics and Gynaecology Research, 35(6), 1054-1060.

13. Blanchard, K., Clark, S., Winikoff, B., Gaines, G., Kabani, G., \& Shannon, C. (2002). Misoprostol for women's health: a review. Obstetrics \& gynecology, 99(2), 316-332.

14. Benrubi, G. I. (2000). Labor induction: historic perspectives. Clinical obstetrics and gynecology, 43(3), 429-432.

15. Fistula, R. Mayo Clinic. Mayo Foundation for Medical Education and Research, 29 May 2010.

16. Abbasi, N., Danish, N., Shakoor, F., Parveen, Z., \& Bilal, S. A. (2008). Effectiveness and safety of vaginal misoprostol for induction of labour in unfavourable cervix in 3rd trimester. J Ayub Med Coll Abbottabad, 20(3), 33-5.

17. Chowdhury, S. B., Nasrin, B., \& Shamim, S. (2005). Comparison of the Safety and Efficacy of Intra-vaginal Misoprostol (prostaglandin E1) with those of Dinoprostone (prostaglandin E2) for Cervical Ripening and Induction of Labour in a
Tertiary Level Hospital. Journal of Bangladesh College of Physicians and Surgeons, 23(1), 12.

18. Sultana, N., Rouf, S., \& Rashid, M. (2006). Oral versus vaginal misoprostol for induction of labour. Journal of Bangladesh College of Physicians and Surgeons, 24(2), 44-49.

19. Wing, D. A., Jones, M. M., Rahall, A., Goodwin, T. M., \& Paul, R. H. (1995). A comparison of misoprostol and prostaglandin E2 gel for preinduction cervical ripening and labor induction. American journal of obstetrics and gynecology, 172(6), 1804-1810.

20. Buser, D., Mora, G., \& Arias, F. (1997). A randomized comparison between misoprostol and dinoprostone for cervical ripening and labor induction in patients with unfavorable cervices. Obstetrics \& Gynecology, 89(4), 581-585.

21. Shetty, A., Livingstone, I., Acharya, S., Rice, P., Danielian, P., \& Templeton, A. (2003). Oral misoprostol $(100 \mu \mathrm{g})$ versus vaginal misoprostol $(25 \mu \mathrm{g})$ in term labor induction: a randomized comparison. Acta obstetricia et gynecologica Scandinavica, 82(12), 1103-1106.

22. Krithika, K. S., Aggarwal, N., \& Suri, V. (2008). Prospective randomised controlled trial to compare safety and efficacy of intravaginal misoprostol with intracervical cerviprime for induction of labour with unfavourable cervix. Journal of Obstetrics and Gynaecology, 28(3), 294-297.

23. Adam, I., Hassan, O. A., \& Elhassan, E. M. (2005). Oral misoprostol vs. vaginal misoprostol for cervical ripening and labor induction. International journal of gynecology \& obstetrics, 89(2), 142-143.

24. Mehrotra, S., Singh, U., \& Gupta, H. P. (2010). A prospective double blind study using oral versus vaginal misoprostol for labour induction. Journal of Obstetrics and Gynaecology, 30(5), 461-464. 